\title{
(С) Д.А. Пятыгина (Хивинова)
}

\section{НАЦИОНАЛЬНАЯ ПРОБЛЕМА СОЦИАЛЬНОГО СИРОТСТВА В ГВАТЕМАЛЕ}

\begin{abstract}
Статья посвящена феномену сочиального сиротства в Гватемале, первостепенной по общественной значимости проблеме страны. В работе автор раскрывает понятие сочиального сиротства, дает описание ситуации и формулирует причины масштабности проблемь, в том числе раскрывает роль в этом вопросе государства и работающих в сфере защчиты прав детей частных некоммерческих организаций. На основании произведенного анализа источников и собственного исследования делаются соответствуюшие выводы и формулируются предположения о возможных путях решения задачи обеспечения прав ребенка в Гватемале.
\end{abstract}

Ключевые слова: сочиильная сирота, Гватемала, защита прав детей, идентичность, устойчивое развитие, проблемы сиротства

Проблема социального сиротства присуща преимущественно странам с низким уровнем экономического развития и отличающимся отсутствием стабильности в сфере внутренней политики. Причем, не удивительно, что особенно остро стоит эта проблема в регионах, где экономическое и политическое положение не стабильно на протяжении долгого периода времени. В таких условиях одной из наиболее ущемленных групп населения становятся несовершеннолетние граждане. Помимо проблемы их личной неустроенности данный фактор закладывает и проблемы будущего страны, так как под угрозой оказывается устойчивое развитие государства. Выход из кризиса, по нашему мнению, может обеспечить не только грамотное руководство страной, но и исполнение соответствующих задач гражданами, которые рационально и осознанно предпринимают шаги по выходу из политико-экономической депрессии, с каждым новым поколением закрепляя достигнутые результаты.

В Латинской Америке наиболее экономически и политически нестабильными являются страны с большим процентом индейского (африканского) населения. К числу таких проблемных государств относится Гватемала. Для данной страны, согласно оценке $\mathrm{OOH}$, характерен средний уровень развития и нестабильная политическая ситуация. Здесь 76\% коренного населения живет за чертой бедности, среди которого $28 \%$ - в крайней бедности, $43 \%$ детей в возрасте до пяти лет хронически недоедают, что считается одним из самых высоких уровней недоедания в мире. Политическая нестабильность, проявлявшаяся на протяжении последних 60 лет в постоянных военных переворотах, а также общая бедность населения привели к появлению колос-

Пятыгина (Хивинова) Дарья Андреевна - Российский государственный гуманитарный университет, м.н.с. Учебно-научного Мезоамериканского центра им. Ю.В. Кнорозова (г. Москва, Миусская пл., д.6), электронная почта: hivinova.daria@ya.ru. Pyatigina (Hivinova), Darya A. Russian State University for the Humnities. E-mail: hivinova.daria@ya.ru 
сального количества сирот, в том числе и сирот социальных в силу происходящего здесь разрушения института семьи.

Социальный сирота - это ребенок, который остался без попечения родителей вследствие лишения их родительских прав, признания родителей недееспособными, безвестно отсутствующими и т. д. (то есть родители живы, но не выполняют своих родительских функций). Соответственно, увеличение числа социальных сирот становится, в первую очередь, проявлением экономического и социального неблагополучия, стресса и в целом признаком ухудшающейся ситуации внутри страны.

Выявить точное число социальных сирот в Гватемале крайне сложно в силу отсутствия переписей и доступа к неблагополучным семьям. Бездомные дети вообще оказываются вне контроля в соответствующих учреждениях. Расчеты, произведенные непрямым способом в архивах занимающихся социальными сиротами организаций, в период собственных полевых работ автора при поддержке Школы политической науки Университета Сан-Карлос (ECP USAC) в Гватемале в июле-августе 2017 г., дают общее представление о состоянии проблемы. Существует также официальная оценка числа сирот и детей в Гватемале. На основании этих данных можно уверенно говорить о маргинальном образе жизни почти пятой части всех несовершеннолетних. Так, по данным ЦРУ, на текущий момент в Гватемале живет около 4 млн детей, и среди них, по оценке фонда All God's Children, к неблагополучным можно отнести более 500 тыс. детей, то есть более 10 \%. Таким образом, социальное сиротство сейчас является проблемой целого поколения, которое пережило времена гражданской войны. И мужчины, и женщины участвовали в событиях гражданской войны, погибали на фронте или становились жертвами военных действий, многие покидали свои дома. Как следствие, родственные, общинные связи оказались разорваны. В этих условиях дети очень часто оказывались объектом использования различных криминальных группировок, что лишь усложнило их жизненную ситуацию и саму возможность возвращения к нормальной жизни. Достаточно большое количество людей в то время мигрировали. В результате, решение столь масштабной проблемы, по нашему мнению, не возможно без делегирования полномочий государственным структурам, располагающим возможностями для исправления и улучшения ситуации с социальными сиротами.

Гватемала ратифицировала “Конвенцию о правах ребенка” еще в 1990 году, что совпало с заключением «мирного договора», прекратившего гражданскую войну. Тем не менее, в сфере защиты прав детей в Гватемале происходят постоянные нарушения. С 1998 г. по 2003 г. стали развиваться программы международного усыновления детей из Гватемалы (DECRETO NÚMERO 77-2007). Они осуществлялись на основании принятой в 1993 г. “Гаагской конвенции о защите детей и сотрудничестве в вопросах усыновления", которая позволила усыновлять детей из неразвитых стран родителями из благополучных государств. Но после 2008-2009 гг. наблюдается резкое ухудшение состояния усыновления вследствие множественных нарушений со стороны, как ни странно, государства. Стоит отметить, что сразу после ратификации международных соглашений, был найден способ легальной продажи детей за рубеж, без контроля и вмешательства надзорных органов Гватемалы. Это привело к тому, что более 98\% детей были усыновлены через частных адвокатов (Intercountry Adoption Guatemala" 2007). Известны многочисленные случаи, о которых сообщала местная пресса, о продаже краденых детей или переданных насильственно в усыновление, а также случаи продажи младенцев нелегальными суррогатными матерями. 
Кроме полукриминальной ситуации с усыновлением детей, в Гватемале существует проблема катастрофического состояния государственных приютов, которые не получают финансирование, выделяемое на их развитие и обеспечение, поскольку средства оседают в карманах чиновников, что сопряжено с высоким уровнем коррупции в стране в целом. За последние три года, под давлением UNICEF началась кампания по закрытию частных приютов, сопровождавшаяся перемещением детей в государственные так называемые “надежные приюты”.

Сам характер участия государства в системе защиты детей вызывает много вопросов. Огромное количество проблем предопределено социальной политикой в сфере детства, которую проводит Гватемала. Ситуацию только усугубляет факт наличия огромного количества несовершеннолетних, вовлеченных в производство (более $20 \%$ от всех детей в стране), а также высокий уровень насилия в отношении детей, распространенность заключаемых в возрасте до 18 лет браков и экстремальная бедность населения. Все это приводит к тому, что социальное сиротство приобрело в стране катастрофические масштабы. Оставленные на произвол судьбы многие из этих детей оказываются вовлеченными в полноценные криминальные группировки (maras), участвуют в наркоторговле, проституции и криминальном бизнесе.

Не удивительно, что в стране существует огромное количество частных организаций, которые декларируют деятельность по оказанию «помощи детям», ставшим по той или иной причине сиротами. В частности, в столице существует два фонда Childhope и PAMI. Подобные организации действуют в разных регионах страны и осуществляют помощь в воспитании и материальной поддержке детей, внедряя программы по запрету детского труда, а также по адаптации детей из индейских общин. Современные технологии позволяют достаточно эффективно собирать средства для помощи детям - например, через краудфандинговые сайты. Нынешняя тенденция к увеличению трат на благотворительность позволяет констатировать, что финансовых возможностей для фондов становится больше, но до детей денежные средства зачастую так и не доходят. Важным фактором, по нашему мнению, могло бы стать взаимодействие фондов с государством, которое на данный момент лишь препятствует работе последних.

Само наличие социального сиротства в стране является индикатором уровня ее экономического развития и состояния. Эта взаимосвязь отчетливо наблюдается в Гватемале: отсутствие доступа к базовым нуждам (еда и медицина), высокий уровень насилия, развитый наркобизнес и наличие криминальных группировок приводят к тому, что многие дети вовлечены в различные нелегальные схемы, начиная от продажи наркотиков и заканчивая продажей самих детей заграницу. Обозначенные отрицательные факторы активно способствуют увеличению количества социальных сирот, которых сейчас только официально насчитывается более $10 \%$ от числа всех детей в стране. Условия жизни негативно сказываются на психологическом состоянии детей и коренным образом воздействуют на их мировосприятие, что зачастую приводит к деструктивному и асоциальному поведению.

Поддержка фондов и некоммерческих организаций по защите детства чрезвычайно важна, однако, они на данном этапе в первую очередь лечат не проблему, а симптомы, поскольку без изменения политической и экономической ситуации в стране, положение вещей никаким образом не сможет измениться, и проблема социального сиротства будет сохраняться и расширяться. Для ее устранения необходимы карди- 
нальные и конструктивные методы, требующие полного переустройства нынешней системы защиты прав детей в Гватемале. В первую очередь, необходимо выработать последовательную национальную политику в отношении детей, опирающуюся на законодательство и ресурсы. Для решения проблемы детства необходимо решение проблемы семьи и общинного взаимодействия, что в сложившихся условиях нереализуемо без наличия экономической и политической стабильности в стране. На данный момент со стороны правительства Гватемалы не предпринимается никаких шагов, которые хотя бы обозначили попытку выхода из тяжелейшего социального кризиса. Складывается впечатление, что существующая ситуация обладает затяжным характером. На восстановление экономики и стабилизацию политической жизни в стране требуется много времени, а без этого никакие продвижения в области защиты детей не смогут увенчаться успехом.

Значимой является проблема, тесно связанная с идентичностью различных групп гватемальского населения. Индейское население, несмотря на преобладающую численность, продолжает оставаться маргинальным в своей собственной стране. Как бы ни казалось парадоксальным, по нашему мнению, для решения проблемы детства следовало бы уменьшить давление международных организаций в отношении дискурса этнических прав отдельных групп населения и сформировать концепцию общенациональной идентичности - тогда задачи по защите будущего страны обретут четкость и целевой вектор.

\section{Источники:}

Human Development Indices and Indicators 2018 Statistical Update. UNDP. http://hdr.undp.org/ sites/default/files/2018_human_development_statistical_update.pdf.

Worldwide Governance Indicators. DataBank. https://databank.worldbank.org/source/worldwidegovernance-indicators.

Guatemala. All God's Children International. https://allgodschildren.org/intervening-for-orphans/ where-we-work/guatemala/.

The world Factbook. Central intelligence agency. https://www.cia.gov/library/publications/theworld-factbook/geos/gt.html.

Brandeis University. Adoptions in Guatemala: Protection or Business? M., 2017. . http://brandeis. edu/investigate/adoption/guatemala.html.

Guatemala. Transparency International. https://www.transparency.org/country/GTM.

Children of Guatemala. Humanium . https://www.humanium.org/en/guatemala/

Helping Save Street Children in Guatemala. The Borgen Project. https://borgenproject.org/streetchildren-in-guatemala.

Children. Childhopeonline. https://www.childhopeonline.org/children/guatemala/

Guatemala. Pami. http://pami-guatemala.org.

Guatemala. Globalgiving. https://www.globalgiving.org/search/?size=25\&nextPage=1\&sortField= sortorder\&selectedCountries $=00$ guatem\&loadAllResults $=$ true.

Giving Statistics. Charity navigator. https://www.charitynavigator.org/index.cfm?bay=content. view\&cpid $=42$.

\section{Научная литература}

LEY DE ADOPCIONES DECRETO NÚMERO 77-2007

"Intercountry Adoption Guatemala". U.S. State Department's online guide for prospective adoptive parents, September 2007 


\section{References}

LEY DE ADOPCIONES DECRETO NÚMERO 77-2007

"Intercountry Adoption Guatemala". U.S. State Department's online guide for prospective adoptive parents, September 2007

Pyatygina (Khivinova), Daria A.

\section{The National Problem of Social Orphanhood in Guatemala}

This article is devoted to the problem of social orphanhood in Guatemala, one of the most pressing social issues in the country. The author reveals the concept of social orphanhood, describes the current situation and identifies causes of this large-scale problem, disclosing the role of the state and private non-profit organizations in protecting the rights of children. Conclusions are made based on the analysis of sources and the author's own research and some ways to solve this problem in Guatemala are suggested.

Key words: social orphan, Guatemala, the rights of children, identity, sustainable development, problems of orphanhood 